\title{
It Starts with an Island: An Empty Terrain in the Danshui River, Taipei and Orz Boyz
}

\author{
David Barton \\ English Department, National Central University \\ Chungli, Tao Yuan, Taiwan 320
}

Tel: 886-09-1133-2474Ｅ-mail: t121274@cc.ncu.edu.tw

The research was supported by the Visual Cultural Center, National Central University

\section{台北淡水河無人島 保留計畫 \\ AN EMPTY TERRAIN IN THE DANSHUI RIVER, TAIPEI}

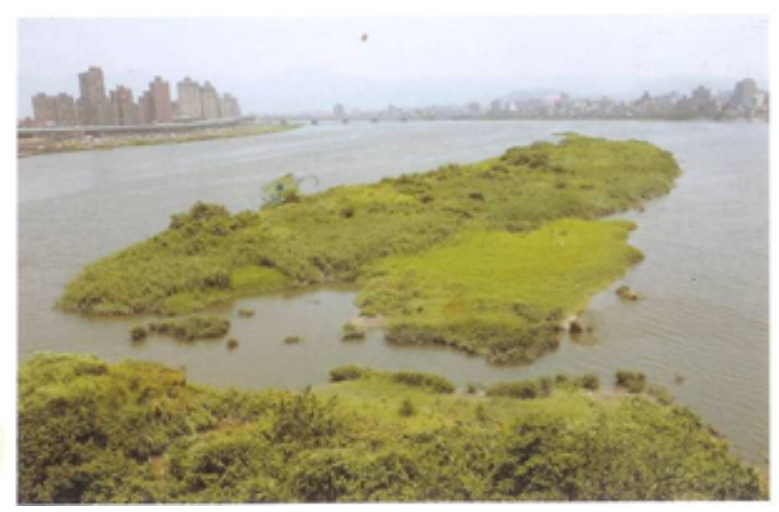

\begin{abstract}
For Slavoj Zizek the empty place or void stands for 'Drive/Death Drive': "a drive is not a primordial, positive force but a purely geometrical, topological phenomenon, the name for the curvature of the space of desire.” (Zizek 2005: 361) This paper examines this 'empty space' in two recent cultural texts relating to Taiwan: one a multi-media presentation at the Taipei Biennial and the other the movie, Orz Boyz. The connecting topology belongs to the topography of islands found in the rivers of Taipei. Both the film and the multi-media project make explicit use of the islands in ways which this paper relates to the psychoanalytic project of Zizek/Lacan. The possible discourses, besides psychoanalysis emerging from these two cultural objects are outlined, but in particular the notion of childhood and underdevelopment/overdevelopment are discussed. From this vantage point, childhood/drive and the symbolic order this paper examines the current predicament of Taiwan from a psychoanalytic point of view.
\end{abstract}

Keywords: The Thing, Symbolic order, Resolution and independence, Intimations of mortality 


\section{The poetry of the uninteresting, the empty terrain}

It starts with an island, An Empty Terrain in the Danshui River, Taipei at the 2008 Taipei Biennial, Taipei Fine Arts Museum. Amidst all the innocuous clutter of the Biennial, there stood a monitor playing varying shots of this 'terrain' with nothing but a brochure on the table next to it explaining this project involves the conservation, for a period as long as possible, of an empty terrain. It is important to maintain terrains of 'non-design', because one can feel free in land that has been left forgotten by town planners. In a few years time, once the surrounding terrains have become more built up, this zone will be the only remaining area of empty land around. Almarecegui 2008: 1

The image seems parodic, set up as it is, solitary island of its own, in the Taipei Fine Arts Museum with all the multicultural litter of the biennial art world surrounding it. It reminded me of the John Ashbery poem, 'Crazy Weather' (Ashbery, 1975: 21):

The proverbial disarray

Of morning corrects itself as you stand up.

You are wearing a text. The lines

Droop to your shoelaces and I shall never want or need

Any other literature than this poetry of mud

And ambitious reminiscences of times when it came easily

Through the then woods and ploughed fields and had

A simple unconscious dignity we can never hope to

Approximate now except in narrow ravines nobody

Will inspect where some late sample of the rare,

Uninteresting specimen might still be putting out shoots,

For all we know.

An Empty Terrain in the Danshui River, Taipei is a video art installation framed by a public museum space, John Ashbery's poem is in a book of poems entitled Houseboat Days and what the two share is the negotiation of a final frontier, non-development and its promise. I would suggest that An Empty Terrain tends toward the naïve rhetoric of environmentalist platitudes but strangely saves itself from that textual world by its simplicity, its "uninteresting-ness." It is a survival from time "before development." One should take this in many ways: "undeveloped" in terms of capitalist development, it is undeveloped; there are no buildings on it. Undeveloped in terms of 'filmed'; it is developed and exposed and therefore it is not undeveloped, it belongs to the history of developed photographic images. In this archive of images, the framing of text which claims the lands 'undeveloped' nature means the image claims to be 'unimagined' or cleansed of development, childlike, Rousseauian, in the midst of massive overdevelopment. This element of the 'image' is made clear in the opening paragraph of its framing text: "In this way, nature will follow a course determined only by whatever spontaneous use is made of the site, by the wind, rain, sunshine, vegetation, river dynamics and by the immediate surroundings."

If we were to play a simple game of semantics, Ashbery's "ambitious reminiscences of times when it came easily/through the then woods and ploughed fields and had/ A simple unconscious dignity" is a simple inter-textual reference to the key texts of Wordsworthian Romanticism, particularly should one think of the poem, 'Intimations of Immortality from Recollections of Early Childhood.'

There was a time when meadow, grove and stream,

The earth, and every common sight.

To me did seem

Apparelled in celestial light,

The glory and the freshness of a dream.

It is not now as it hath been of yore; -

Turn wheresoe'er I may,

By night or day,

The things which I have seen I now can see no more.

As current environmental prose stems from Romanticism, Rousseau, Wordsworth et al, the sentence; "In this way, nature will follow a course determined only by whatever spontaneous use is made of the site, by the wind, rain, 
sunshine, vegetation, river dynamics and by the immediate surroundings," is not undeveloped at all. It is also largely over-determined, to begin with by the discourse of climate change. It would appear, according to climate change discourse, that nothing on earth is "undeveloped" by human development. However, these origins, these undeveloped spaces, these promised 'beyonds' and 'befores' clearly strike a deep psychological chord in terms of human interactions with the environment.

\subsection{Zizek's Symbolic redemption of the empty terrain}

If one were to look at another island in the stream of human culture; that projected on the planet Solaris at the end of Andrei Tarkovsky's movie of the same name, then the undeveloped project would have to be, as Slavoj Zizek has it in his documentary, The Pervert's Guide to the Cinema, 'redemption.' In the science fiction movie, the absolution of the son by the father, according to Zizek, drives the uncanny image of the spit of land on the burning Id of the planet Solaris as cleansed of the impurity brought to men by women. Thereby the 'empty terrain' cinematically projected at the end of Solaris is an island of male purity, of male innocence, or redemption, an Eden before or after Eve, somewhere lost in outer space.

\subsection{The gendered subject of the empty terrain}

So far, empty terrains inaugurate discourses, particularly of childhood, or nature, or the prelapsarian, Edenic garden world of childhood. "You are wearing a text," Ashbery writes. You are draped in the discourse of childhood, of fairy tale, "the glory and freshness of a dream," as Wordsworth comments. However, if one is to look at the obverse side of that empty terrain, the dark side of the fairy tale, you are the invisible object of that text, an erased subject, not there. "Where man is not, nature is barren," as William Blake put it succinctly in The Marriage of Heaven and Hell. Therefore "you' must wear a text or there is no point to "An Empty Terrain in the Danshui River, Taipei," literally no point. The subject, 'you' must be buried in that empty terrain as in Wordsworth's "A Slumber Did my Spirit Steal:"

A slumber did my spirit seal;

I had no human fears:

She seemed a thing that could not feel

The touch of earthly years.

No motion has she now, no force;

She neither hears nor sees;

Rolled round in earth's diurnal course,

With rocks, and stones and trees.

An Empty Terrain in the Danshui River with its appeal "nature will follow a course determined only by whatever spontaneous use is made of the site, by the wind, rain, sunshine, vegetation, river dynamics" is a failed appeal for the death of the human in the Danshui River, the silence of human discourse, the recession beyond the symbolic castration that led to Lacan's "parle-etre" in the first place. (Note 1) Its failure is what makes the piece interesting, obscuring the presence/non-presence of the human. Of course in Tarkovsky's Solaris, as in Wordsworth's "Slumber" it is the woman or girl who must be erased in order for desire to retreat to its pre-Oedipal state. This is interesting because, subjectively, the empty terrain in the Danshui River 'looks' feminine, a green patch of mother earth in the middle of two drowning legs. One wants to return to the silent mother, the dead drowning of a Virginia Woolf, almost to the extent that one could blame the need for this Empty Terrain in the Danshui River on Taiwan's phallocentric culture. I don't think anyone would deny that the habitable part of Taiwan, that one third of the island that is not overly mountainous, is overdeveloped. Nor would many debate whether or not it was men who, for the most part, are to blame for the development. There has not been a sustained debate between men and women on whether or not to develop the island of Taiwan. Equally it is a woman who has mounted the exhibit at the Taipei Biennial, and not a Taiwanese woman, which further confuses the issue. One could place this exhibit in an emerging convergence of the environmental movement in Taiwan and the feminist movement. (Note 2) But then it would be necessary, probably, to invoke some form of 'feminine mystique' or 'mother' nature, an exclusionary discourse. All of these discourses, besides the environmentalist, are erased from the brochure accompanying the video. I would suggest the simplicity of this video display is enormously over-determined and thereby very effective. It certainly caught my attention by everything it left out.

\subsection{Poetry and Zizek's 'sacred place of impossible jouissance'}

The crucial dimension of the Lacanian concept of the Symbolic is this logical priority, the precedence of the (empty) place with respect to the elements that fill it: before being a collection of 'symbols', bearers of some 'signification', the Symbolic is a differential network structured around an empty, traumatic place, described by Lacan as that of das Ding, the 'sacred' place of impossible jouissance. Zizek 2005 
I have incorporated snippets of post-modern and romantic poetry thus far in this essay in order to invoke this "empty, traumatic place... Sacred place of impossible jouissance." In Wordsworth's "A Slumber did My Spirit Seal" this place becomes the funeral mound of a young girl, which in turn becomes the entire world as a grave. In John Ashbery and Wordsworth it is the place of "rare, uninteresting specimens" of "things which I have seen I now can see no more." Each of these poems is arranged around "an empty, traumatic place," literally death, or metaphorically the death of the symbolic space of childhood. In the video of the empty terrain in the Danshui River I see all three of these poems. They all allude to something that is empty, das Ding, and yet full of emptiness, of wonder, of the possibility of deathless life in the imagination.

\section{Orz Boyz and a fairy tale of Taiwanese childhood}

As I am attempting to demonstrate, An Empty Terrain in the Danshui River, Taipei elicits many discourses. However, to return to childhood, to a prelapsarian garden of undeveloped terrain, I would like to examine the current Taiwanese film, Orz Boyz, and its representation of childhood in the ROC in connection with this exhibit from the Taipei Biennial. Written and directed by Gilles Yang Ya-Che, and winner of two awards at the Taiwan Golden Horse Film Festival, the movie, according to the director, "was a way to live the life [I] never had." (Tsang 2008) The film begins with a camera shot of a crude chalk cartoon drawing of a family on the concrete spillway underneath a bridge. It will continue this alternative narrative of the imaginary, cartoon world contrapuntally punctuating the non-cartoon world of the boys, named Liar \#1 and Liar \#2, (because they are always telling lies to get out of trouble in school.) Liar \#1 has a mentally ill father and lives on a piece of land jutting into a river, which river we are not told. His mother, again for unexplained reasons, has left the father and the son for Hawaii. Liar \#2 lives with his Amah, his grandmother, having also been abandoned by his parents for untold reasons. The crude cartoon drawing of the family, with which the film begins, gives way to a sophisticated animated update of the Oscar Wilde fairy tale "The Happy Prince." (Note 3) The narrative of "The Happy Prince" is slightly altered in this Taiwanese version, however, it reflects the basic fundamentals of the fairytale. In the fairytale as in the movie and its voice over narration, the poor are overseen by a protective father figure who gives away all his wealth and then collapses. However, as opposed to the Prince of the fairy tale, the father figure of Orz Boyz is a Japanese style 'Transformer' like toy named Kada King.

\subsection{Hyperspace as the intersubjective network of friendship}

Here is where the Taiwanese alteration of the fairy tale becomes interesting, if as Slavov Zizek suggests:

a child endeavours to dissolve, by way of their fantasy, the enigma of the role they play as the medium of interactions between their mother, their father, all their relatives, etc: the enigma of how mother, father and others fight their battles, settle their accounts through them... Parents fight their battles through them, but it is not clear to them what their role is in this complex, intersubjective network into which they are thrown. Zizek 2005: 58.

The lack of competent parents in the movie makes this attempt to understand who they are in the symbolic family structure determined by abandonment. The construction of adult intersubjectivity between overworked grandmother and insane father, leaves Liar \#1 and Liar \#2 to figure out what is invested in them between themselves, the abandoned. One would suggest that abandonment is the background behind the complex relationship between 'make believe' and 'lying' in the story. In other words the movie is the story of Liar \#1 and Liar \#2's investment in fantasy and friendship in lieu of parental protection; they only have one another. They are part of the Peter Pan "Lost Boyz" tradition of childhood narrative. This is made quite clear by the chorus, repeated at various intervals throughout the movie and by various characters, "adults all lie." The only adult, \#1 tells \#2, who does not lie, is his father. The mentally ill father has told \#1 and \#1 has convinced \#2 of the authenticity of a perfectly happy place, the impossible place of jouissance to interpolate Lacan, away from the world of adult lies and abandonment, a world called 'hyperspace' which we would recognize as the science fiction version of Neverland. This hyperspace will take shape on the empty terrain in the river upon which Liar \#1 and his crazy father live. This topological void is the place empty of significance and yet compelling significance. It is where the Real, in Zizek's reading of Lacan, forces the construct of the symbolic structure in the absence of the father. Again I would like to interrupt this narrative by indicating the importance of outer space to the structure of subjective symbolization in Tarkovsky's Solaris. Here again in Orz Boyz a fantasy space, 'hyperspace' is constructed by children to escape the intolerable burden, increased by abandonment, of growing up (to be liars, one must recall, or rats as adults are later invoked in the movie, but which is synonymous with liar.) There are no positive adult role models in this movie. There is no way for the boys to "negotiate the enigma of the role play as the medium of interactions between their parents" except through the construct of Kada King as the protective father figure of the hyperspace world. From their construction of Kada King on this empty island they are seeking to build relationships with the father, the unreal father or Big Other (in Zizekian terms) of the Super Ego. I would suggest the movie actually questions the possibility of such a thing as positive adult role models in Taiwan; a question to which I will return in terms of Taiwan's 'overdevelopment.' 


\section{The absent father of the nation}

Besides the toy father, Kada King, which is both animated as part of the cartoon subplot of the movie and a special toy for sale at the toy store in the Taipei neighborhood where the boys live, there is another inanimate father figure in the movie, the statue of an old soldier standing in salute in \#1 and \#2's schoolyard. This relic of the Chiang Kai Shek era, of the migration to Taiwan of Chiang Kai Shek's one million strong army in 1949, is an object of fascination for the boys, who, as bad boys, are constantly looking out the school window, whether in detention or during break. The school, along with the traditional market where \#2 lives and the riverside peninsula where \#1 lives form the three backdrops of the movie. As the movie was made recently (2008), it invokes Chen Shuei-bien's erasure of symbols of the era of Chiang Kai Shek; the old soldier is removed from his plinth and deposited in the basement of the school. Again, a father figure, a father of the history of Taiwan, a Chiang Kai Shek figure, is removed from the children's world, but he is not forgotten. \#1's father has supposedly told his son "all bronze statues are from hyperspace." In other words all fathers are imaginary symbolic constructs. So, with the help of their friends, \#1 and \#2 move the statue from the basement to the riverside shack/dock/spaceship of \#1's father. I say dock and spaceship because it is from the shack that the boys will get to confront the empty traumatic island of das Ding from which they will take off for hyperspace to live with their imagined father. They are followed in this parade carrying the old soldier from the school basement to the river, by the father waving a small flag, which may or may not be a Taiwanese flag. Ironically the mentally ill father seems to be symbolizing the present state of Taiwan. As symbols of the future and the past, the science fiction Kada King and the Old Soldier, leave the period of the 'now' obviously open for debate. The question underlying the entire film is, who is the father now in Taiwan? Has the father gone mad? Has the father abandoned Taiwan for Hyperspace?

\subsection{Propulsion of desire and the death drive}

We have two, actually three, phallic authorities guaranteeing the Lacanian symbolic order of 'hyperspace,' the space of phallic jouissance: the old bronze soldier, the mentally ill father and Kada King. Here there is ample space for the fantasies of the boys to dissolve the enigma of their identities as outcasts, although there seems no place to resolve their dilemma of psychological investment in the symbolic order. After all, they are Orz Boyz, out of place or displaced. (Note 4) This triangulated phallic power is further disturbed by the introduction of a girl, a young girl named Ally Lin, to the intersubjective structure of the friends, the Amah and the mentally ill father. Liar \#1 in particular seems disturbed by his nascent libidinal desires in relation to Ally Lin. The character Ally Lin attracts \#1's attention and \#2 teases him about it. What attracts both of their attention is her strange smile, perhaps an Orz smile. She is always smiling a strange smile. This is odd, the boys believe, because her mother has just died. \#2 at one point in the film confronts Ally Lin with the impossibility of her mother's death, asking, "Why do you smile like a ghost. Your mother is dead." The intimation of mortality, naively blurted out, becomes too much for the boy, he cannot bear her look, nor the tears welling up in her eyes, and he runs away. My point in weaving in quotations of the poems with which I began this essay is in essence to construct a skeletal structure of texts around the empty space in the Dashui River all of which points to the ghostly nature of emptiness itself, that which calls out for representation but cannot be represented. The motif of death which runs throughout the Orz Boyz is played out explicitly here. Soon after this confrontation, \#2 has to deliver a death homage palanquin to Ally Lin's family. In her empty and echoing apartment block he hears a voice repeatedly asking, in Alice in Wonderland fashion: "Who are you?" Deciding it is a bird Liar \#2 answers this classic Oedipal question, "Stupid bird, I am the dead guy." However, this answer to death with "death' returns with the echoing of the bird, "I am the dead guy." This is the Zizekian "undead father," the father or "Big Other" which cannot die. It is not Real, although it is a terrifying confrontation with the Real, it is an echo, an intimation of that which never dies. This answer from the bird, which we never see, again overwhelms \#2 and he wets himself in front of the bereaved girl Ally Lin. \#2 does not understand the relation between desire, death and the maiden "Rolled round in earth's diurnal course,/With rocks, and stones and trees."

The boys are attracted to Ally Lin, obviously because she shares, through her smile, some of their ambiguity concerning the world of adults and the relation of that world to death. \#1 with the help of \#2 proceeds to catch Ally Lin's attention; they act foolishly with scatological jokes about their teachers, make her laugh and eventually initiate Ally Lin into the reality of 'hyperspace.' Hyperspace, in a scene concocted of tatamis, fans, ribbons and pillow feathers, becomes a place to escape tragedy, to revel in a child's imaginary jouissance, which might actually be better called a child's resistance to the Zizekian Real, or for these Taiwanese kids 'resistance jouissance.'

\subsection{The global father, Taiwan's predicament}

Ally Lin before leaving the neighborhood gives \#1 and \#2 a thank you note and an explanation for her strange smile. Shoring up \#1 and \#2's resistance jouissance of 'hyperspace,' she writes: "keep smiling and you won't be afraid, my mother taught me that." For a movie masking deep fear and loss in the Taiwanese context the possible sentimentality of the soap opera shows its face and yet does not obscure the deeper intersubjective plight of these children. Actually the intersubjective plight of the children can be read as an allegory for the island of Taiwan. With the departure of Ally Lin the narrative turns to the competition to win a 'limited edition' Kada King doll from the toy store. A numbered script is 
hidden in one of the vending machines outside the toy store; the winner of the correct vending ball with the script inside will win the doll. Of course the boys, \#1 and \#2 are already heavily invested in the libidinal Kada King toy as their key to the kingdom of hyperspace, thereby this 'limited edition' appears invaluable. The key to the allegory here is the fact that the Kada King is expressly said, by the malicious store owner, not to be from Taiwan: "it is an import." Without invoking Taiwan's subaltern status in terms of Japanese globalization and culture, the point is made; the boys explicitly lack even a local Taiwanese toy to which to attach their father fantasies, they are adrift once again, in terms of identity, imagining a father figure composed of the colonial powers of Japan, Oscar Wilde's England, Tom Sawyer and Huckleberry Finn's America. Still, Kada King is the only father projected from the confrontation of the Real and the symbolic empty terrain. The boys have a plan besides winning the Kada King import to accessing their fantasy 'hyperspace.' They have to go to a waterslide on the outskirts of Taipei and ride the largest slide a hundred times before they will be automatically beamed out to 'hyperspace.' In relation to my own development of a poetic intertextual structure relating to empty, uninteresting terrains I find this waterslide to be almost too literal an example of Zizek's description of Lacan's 'das Ding' where he writes the Symbolic is a "differential network structured around an empty, traumatic place... the 'sacred' place of impossible jouissance." Zizek 2005 Imagined from the empty terrain outside Liar \#1 father's house the waterslide park stands in the movie for the ultimate escape into 'hyperspace.'

\section{The representation of emptiness in a Symbolic terrain}

It is necessary to introduce the crucial distinction between 'symbolic signification' and its own place, the empty place filled by signification: the Symbolic is above all a place, a place that was originally empty and subsequently filled with the bric-a-brac of the symbolic order. Zizek 2005

I quote Zizek here in order to reinforce what I have been attempting to construct in this essay. The boys have no fathers but that does not mean they are not engaged in the 'symbolic signification' necessary to their entering the adult world. They have the Symbolic and it is a place that was originally empty and they do fill it with the bric-a-brac of Kada King's Hyperspace. This is where I would build a bridge between An Empty Terrain in the Danshui River from the Taipei Biennial and the empty terrain as it appears in the movie Orz Boyz. In the movie it is introduced as a tidal berm, seaparated from the land at high tide and connected at low tide. The first appearance of this terrain shows the boys watching \#1's father, all of them positioned on this empty terrain, as the father enacts a libidinal Chaplinesque grief stricken dance with a broken umbrella. The assumption is that he is communicating his longing for the return of his sanity, the return of his wife from Hawaii, or simply a grief stricken moment of rapture. The boys smile at one another, appreciating the difference of the only adult who does not lie. I say libidinal dance because the empty terrain is framed in the movie as the place where this dance should happen. As Zizek notes in The Pervert's Guide to Cinema, "our libido needs an illusion in order to sustain itself." The libidinal element in the movie was initiated by Liar \#1's interest in Ally Lin. In particular the illusion which compelled that desire was her smile, her smiling the smile of her dead mother, her confrontation with the Real. The manic superego of the father finds this illusion on the empty terrain, where the symptom of the illusion, the dance, is witnessed by the boys. This terrain is similar to the empty planet Solaris, what Zizek calls, "the Id machine," beaming the illusion of a woman, a wife who has committed suicide, into her husband/psychologist's spaceship. Liar \#1's father's illusion is not represented except in the dance on the empty terrain I am equating with Zizek's Id machine.

The empty terrain in Orz Boyz appears a second time, this time not as the empty ground of the father's fantasies, but as the cluttered ground of the boys' fantasy. \#1 has convinced \#2 of the truth of 'hyperspace.' The two boys are bouncing on a discarded trampoline washed up on the empty terrain, their hands shaped like binoculars held to their eyes trying to see 'hyperspace.' They start to yell "I can see it, I can see it." It is from this second framing of the empty terrain that \#1 convinces \#2 he can see 'hyperspace.' That is when, while resting on the empty terrain, they decide upon the plan to gather recycling material, bottles and whatnot to make the money to go to the waterpark. This second time the terrain is framed, it is covered with refuse, 'bric-a-brac,' washed up by the tide. The father's libidinal illusion, a broken and rapturous dance, seems to have consecrated the terrain as a place of symbolic importance, it is the place of symbolic signification.

\subsection{The heroism of loss}

The story continues with \#1's intense search for ways to make money in order to realize his dream of getting to 'hyperspace' through a trip to the waterslide. \#2 obediently plays along, however, his attention is divided between the waterslide trip and the Kada King doll. The hierarchy of childhood with \#1 always being \#1 and \#2 his sidekick begins to fall apart when \#2 spends some of his precious waterslide savings on a try for the vending machine ball. He wins the script and the Kada King doll. However, the malevolent toy store owner reneges on the deal, offering money for the doll or telling \#2 he will have to wait two weeks until another "import Kada King" can replace the old. \#1 takes the script from \#2 and demands the money, thinking the trip to the waterslide will be uppermost in \#2's mind as it is in his own. It is not. The trust between the two friends is broken by the outrageous and hysterical claim of a furious \#2 that "hyperspace is a lie." With the friends at loggerheads, both their dreams of entering 'hyperspace,' \#1 through the 
waterslide, \#2 through the auspices of Kada King, shattered, \#1 takes out his frustration against the adult world. He attacks the toy store with a rock and is subsequently apprehended and supposedly taken from his ill father to a reform school. \#2's desperate attempts to get his friend freed from this fate are thwarted first by his Grandmother's indifference and secondly by \#1's father's mental illness. The father clutches \#1's hand in his own and draws it to his heart. He then utters the only actual word he speaks in the movie, 'tong' or in English, 'hurt.' They wail together against fate. This desperate, almost obscene keening of the father and the boy, this wailing from the realm of the super-ego, from the realm of justice/injustice, leads immediately to a frame of the empty terrain in the river. The island that was once covered with garbage is now cleansed, one assumes by tidal activity coming up river from the ocean. \#1 and \#2 are separated, split apart as it were. The bric-a-brac of childhood has been cleared away. There is nothing left to do but grow up, as Zizek puts it:

... one has to maintain desire in its dissatisfaction. What we have here is a kind of heroism of the lack: the aim of the psychoanalytic cure is to induce the subject to assume his constitutive lack heroically; to endure the splitting which propels desire. A productive way out of this deadlock is provided by the possibility of sublimation, when one picks out an empirical, positive object and "elevates it to the dignity of the Thing, i.e., turns it into a kind of stand-in for the impossible Thing.” Zizek 2005: 191.

\subsection{The escape from loss to hyperspace; the waterpark}

The stand in for the impossible "thing" is posited in Orz Boyz, not only as the Kada King, but also as the magnificent water park next to the ocean. It arcs and curves symmetrically around and up, through and over an intricate network of scaffolding. Allegorically the water park in particular stands in for the heroic adventure of propelling desire in a Lacanian sense. (Note 5)

This wailing of the super-ego, to echo Zizek's description of the father figures in David Lynch's movies, is obscene, but obscenely sad, encapsulating the immense grief structuring the entire film. The subsequent framing of the empty terrain of the tidal berm, the third and final time we see it, is ambiguous. It is cleaned of the garbage it was strewn with in its second viewing when the boys are advancing their dream of 'hyperspace.' It is silent, against the background frame of the wailing father and boy. It is just there, empty in the calm of the river. One might suggest this is the end of childhood, the heroic constitutive lack of which the Lacanian Zizek writes. Or as Ashbery writes in the poem Crazy Weather; "the proverbial disarray/Of morning corrects itself as you stand up./You are wearing a text."

The question is, what is this text in the context of Taiwan. The proverbial disarray of childhood has been erased, subjectivity arises in its adult context. The water park puts \#2 to the test and the movie achieves resolution with \#2 framed finally grown up, as a lifeguard at the park. Loss, mental illness, prison, poverty, as well as the supreme fantasy of escape are gone. That was childhood, the things of childhood are to be put aside. There is a great deal of "goodbye" in this film, it is a film about transition out of childhood. Yet the intense grief with which childhood is associated remains: Ally Lin's heartbreaking smile as well as the boys desperate attempts to deal with their disadvantages, all of which are thwarted, are not redeemed. There is the discussion of the famous ' 2 grams' released by the body at death overheard on a radio broadcast as the shack/dock/spaceship of the mentally ill father is fore-grounded and then the separation of \#1 and his beloved, non-lying, father. Finally there is the free for all howl of grief shared by the father and \#2 preceding the final framing of the empty terrain in the river.

\section{5.}

I would suggest that the empty terrain in the Danshui River witnessed at this year's (2008-09) Taipei Biennial and then fortuitously fore-grounded in the movie Orz Boyz remains empty, the symbolic heroism of subjectivity in Taiwan is not yet 'wearing a text.' The country is in mourning for its childhood, a childhood that was anything but innocent, rather a childhood of poverty, death and injustice. The movie does not answer the question, has the father of the nation gone mad, unable to heroically adjust to its separation and independence?

The identity politics that are often brought up as the crux of the island's situation at the moment would seem to be preventing the island from developing itself on the empty terrain. The object of desire, which seemed under Chen Shui-bien to have been nationalistic in content, has been rather abruptly shattered, and one might say good riddance. However, no new object has arisen to take its place. The old soldier has been removed, but not forgotten. He, along with the possibility of the influence of Japanese globalization of Taiwan in the doll Kada King, remain in 'hyperspace.'

\subsection{Orz Boyz and the fairytale of loss}

One of the stranger features with which to conclude this discussion of Taiwan's empty terrains comes from the director of Orz Boyz himself. At the beginning of the discussion of the film I quoted Gilles Yang Ya-che as saying his work was a way of living a life he had never had himself. To fill out that remark from a question and answer interview I discovered online, Yang Ya-che goes on to say: 
[I] created this strong bond between these two little boys because as a child [I) never had a relationship like that. [I] was usually the kid in the library studying hard, and this film was a way to live the life [I] never had. Tsang 2008: 1

Considering the desperate straits of the two friends, the overwhelming melancholy of the film and its death obsession, one wonders how this could be a wished for childhood. And yet, for someone locked in the library for the duration of childhood Orz Boyz is a fantasy come true. Obviously the idea of friendship, lacking in Yang's youth, was enough to eradicate the idea of parents or responsible adults of any kind. This is what I was questioning when I suggested the movie questioned the very possibility of a 'positive' adult role model. In Taiwan, adults mean not friends but libraries, not playing at 'hyperspace' but studying. Death, poverty and abandonment all seem preferable to libraries and studying. This strikes a profoundly miserable chord with the empty terrain of Taiwan's overdevelopment. One has to imagine the worst of all possible psychological scenarios, mentally ill fathers, overworked grandparents, failure at school, in order to escape the reality of the middle class parental demand for competitive achievement, incredibly bland, if comfortable, living spaces (apartment blocks), and no imagination.

In this context an empty terrain in the Danshui River, Taipei, appears suicidal; get me out of the library and give me a friend or give me death. However, as the movie is the compensation for the emptiness of a childhood spent in the library without friends it again reflects on the empty terrain as the prison like space from which a child will build the fantasies upon which to construct a future. This positive scenario is reflected by the end of the movie in which Liar \#2 has grown up to be a lifeguard, helping other kids to reach 'hyperspace.' The quandary remains, only those kids who can afford the fairly exorbitant entrance fee, 1,000 NT, can attain 'hyperspace.' Thereby it is a terrain owned and developed for kids in libraries who don't get to visit very often. The paradox remains in the film that the preferred condition of childhood in Taiwan is miserable. Look at all the fun the poverty stricken kids with mentally ill or absent or dead parents have in the movies. However, this seems to be a paradigm of children's stories and movies. Tom Sawyer is being brought up by his Aunt Polly after his mother dies, his father is not mentioned; Huck Finn's father is a drunk, his friend Jim is an escaped slave; Peter Pan himself is developed eventually as an escaped orphan. Even Bambi's mother is shot before the fun begins. The escapes of Neverland, the Mississippi River, Bambi's wilderness and 'hyperspace' all belong to the same childhood fantasy structure. They all contain the 'thing' empty of symbolic meaning, without mother, without father, without authoritative phallus.

\subsection{Resolution and Independence?}

This is where I would like to return and end this discussion, the burial of the 'thing' on An Empty Terrain in the Danshui River, Taipei. Having used poetry as my frame throughout this paper I would like to conclude with the anamorphic image embedded in Wordsworth's 'Resolution and Independence'. (Note 6)

ix

As a huge stone is sometimes seen to lie

Couched on the bald top of an eminence;

Wonder to all who do the same espy,

By what means it could thither come, and whence;

So that it seems a thing endued with sense:

Like a sea-beast crawled forth, that on a shelf

Of rock or sand reposeth, there to sun itself;

$\mathrm{X}$

Such seemed this Man, not all alive nor dead,

Nor all asleep - in his extreme old age:

His body was bent in double, feet and head

Coming together in life's pilgrimage;

As if some dire constraint of pain or rage

Of sickness felt by him in times long past,

A more than human weight upon his frame had cast.

Here again we have an empty terrain haunted by a man 'not all alive nor dead.' This thing, the leech gatherer of the poem, is both human and not human, an image both of the earth and of man. One thinks of the mentally ill father of \#1 dancing on the empty terrain, although Wordsworth's leech gatherer is far from mentally ill. One also thinks of the undead father confronted by Liar \#2 in Alley Lin's apartment building: "I am the dead guy." And this may be the crux of the problem in terms of Taiwan's overdevelopment thing. The symbolic father, the film's leech gatherer, is mentally 
deranged. He has not been able to heroically come to terms with his separation, nor with the propulsion of his desire. The U.K. example of Peter Pan and the American example of Huckleberry Finn stand in a different relation to the 'thing' than does the Taiwan example of the Orz Boyz.

$\mathrm{xi}$

The old Man still stood talking by my side;

But now his voice to me was like a stream

Scarce heard; nor word from word could I divide;

And the whole body of the Man did seem

Like one whom I had met with in a dream;

Or like a man from some far region sent,

To give me human strength, by apt admonishment.

This human strength of the anamorphic image of the leech gatherer in a poem called "Resolution and Independence" is what might be questioned in the Orz Boyz. Resolution Taiwan has, but not independence. Here is where I think the empty terrain 'couched' on the Danshui River and its literary/psychoanalytic analysis gives way to another discourse, that of poverty and alienation in the age of globalization and the place of the left, or the lack of the left in the midst of the shambles of national identity currently plaguing Taiwan's independence issues.

\section{References}

Almarcegui, Lara. (2008). An Empty Terrain in the Danshui River. Taipei: Taipei Fine Arts Museum.

Ashbery, John. (1975). Crazy Weather. In John Ashbery, Houseboat Days. New York: Penguin Books. P. 21.

Blake, William. (1958). Marriage of Heaven and Hell. In J. Bronowski (Ed.) William Blake. Middlesex: Penguin Books, p. 98

Tsang, Mathew. (2008). Orz Boyz. [Online] Available: http://www.schemamag.ca/VIFF2008/2008/2009/orz_boyz.html (September 30, 2008)

Wordsworth, William. (1950). Ode: Intimations of Immortality From Recollection of Early Childhood. A Slumber Did My Spirit Seal. Resolution and Independence. In M. Van Doren (Ed.) William Wordsworth Selected Poetry. New York: The Modern Library, p. 541, 158, 468-469

Zizek, Slavoj. (2005). Interrogating the Real. London: Continuum, pp. 45, 58, 191

\section{Film References}

Fiennes, Sophie. (2006). The Pervert's Guide to Cinema. Lonestar, Mischief Films, Amoeba Film Production

Tarkovsky, Andrei. (1972). Solaris. Visual Program Systems

Yang Ya-che. (2008). Orz Boyz. 1 Production Film, 2008.

\section{Notes}

Note 1. The anamorphic 'she' that is phantasmatically entombed in "earth's diurnal course" is the speaking/non speaking being which Zizek discusses as the eternally returning undead of the death drive in his discussion of Hitchcock's Vertigo in The Pervert's Guide to the Cinema. This being appears in Orz Boyz as the echo of Liar \#2 in the apartment of Ally Lin, "I am the dead guy!)

Note 2. Indeed, special thanks are given at the end of the brochure to the PeiHai Water Life-Saving Association,

Water Resources Agency, Water Resources Bureau, etc. This exhibit was certainly meant to galvanize Taiwan's environmental protection movement.

Note 3. "The Happy Prince" may be the meta-narrative structuring the literature to film element of Orz Boys, however there are many other children's literary precedents which I will discuss in the film, including: Peter Pan, Alice in Wonderland, Huck Finn.

Note 4. Orz is an emoticon from Japan denoting failure and despair. Again, even the title of the film relates to Taiwan's predicament in terms of Japanese globalization.

Note 5. Here, of course, I am cross-referencing the aforementioned quote from Zizek: "the Symbolic is a differential network structured around an empty, traumatic place, described by Lacan as that of das Ding, the 'sacred' place of impossible jouissance." Zizek 2005: 45. It is difficult not to see the water park and its connection to 'hyperspace' as just such a place of 'impossible jouissance.'

Note 6. I simply wish to make note that in writing this essay I have constructed my own water park of poetic quotations in order to provide a scaffolding of literature for insight into the psychoanalytic structure of the film Orz Boys. I want to keep my own discourse trembling, paratactic, due to the propulsion of poetic desire sliding over it. 